\title{
The Deployment of Next Generation Access Network in the EU: Facts and Analysis of Regulatory Issues
}

\section{Kazi Milon}

Master Student, Faculty of Society and Economics, Rhine-Waal University of Applied Sciences, Germany

Md. Nur-Al-Ahad

Master Student, Graduate School of Engineering, Toyohashi University of Technology, Japan

\section{A.B.M. Monjurul Alam}

Master Student, Faculty of Society and Economics, Rhine-Waal University of Applied Sciences, Germany

\begin{abstract}
This paper summarizes the existing level of penetration of next generation access network across the European Union and regulatory challenges and solutions to the deployment of this network. It also outlays comparative scenarios, facts and figures, pertaining to European countries, in terms of NGA coverage, speed, subscription rate and geographical region etc. The main purpose of the paper is to portray a comprehensive view of the ongoing scenario of NGA network and regulatory dimensions for the implementation of next generation access network. The design of the research has three phases. Firstly, the paper encompasses current facts and issues, in the realm of NGA infrastructure, based on secondary data over a period from 2012 to 2017. The paper compiles annual data pertaining to coverage, speed, subscription rate, geographical region and trend over time etc. Secondly, the paper critically reviews regulatory issues based on existing theoretical and empirical works of literature. Finally, it reveals certain aspects of regulation e.g. co-investment, asymmetric and symmetric access regulation, and geographic segmentation and their varying implications in different conditions. The findings do not cover all aspects of regulation and further research is still needed to find socially optimized regulatory solutions.

However, the study is highly significant to the EU commission, local government, policy makers, academicians and prospective investors to guide all of those related stakeholders to successfully replace copper to fiber network, pursue their vested interests and create an atmosphere for economic transformation of high-speed broadband infrastructure.
\end{abstract}

Keywords: Next Generation Access Network (NGN), European Union, high-speed internet, internet access, fiber-optic technology.

JEL Classification: M15, O32, O38.

Cite as: Milon, K., Nur-Al-Ahad, Md., Monjurul Alam, A.B.M. (2018). The Deployment of Next Generation Access Network in the EU: Facts and Analysis of Regulatory Issues. Business Ethics and Leadership, 2(4), 617. http://doi.org/10.21272/bel.2(4).6-17.2018.

(C) The Authors, 2018. This article is published with open access at Sumy State University.

\section{Introduction}

The era of ICT (information and communication technology), network access has been developing gradually across the globe. The broadband technology has become a very significant platform to contribute to the economic progress of the country. A Study conducted by World Bank shows that an increase in 10 percentage point of broadband diffusion leads to greater GDP growth about $1.21 \%$ increases in developed countries, at the same time it is highly associated in low earning countries and middle earning countries with GDP growth $1.38 \%$ raises. The broadband technologies have moved to forward to the next step with new technology from copper network to fiber-optic network. Next Generation Access (NGA) networks refer to the upgraded version of broadband network technologies supplied through the fiber-optic system to ensure the high-speed internet facilities for the domestic and commercial consumers in the market. Bresnahan and Trajtenberg (1995) argued NGA networks indicate a basic technological objective and desire to motivate the symbolic development of productivity and expansion across significant economic zones. The European market is one of the largest markets in the world where some EU countries are doing well in term of NGA deployment. But, surprisingly most of the EU member states stay behind from NGA technology compare to non-EU developed countries in 
the world including Japan, Korea, Taiwan and the U.S. (FTTH Council Europe, 2015; Yoo, 2014; OECD, 2013; Briglauer and Gugler, 2013). The European Commission perceived the importance of ICT in their flagship action. EU commission plans to pay close attention to digital communications technologies in order to improve the competitive market in Europe' economy. In 2010, the European Commission set up the digital agenda strategy for Europe where NGA has been included. EU commission has determined to deploy the NGA networks across the EU zone by 2020. The European member states are far behind from NGA (fiber-optic) technologies where the EU' Digital Agenda designed with a promise to deliver 100\% coverage of internet access with $30 \mathrm{Mbps}$ access speed for all EU citizens by 2020 and $50 \% \mathrm{HH}$ penetration with $100 \mathrm{Mbps}$ service by 2020 . It is widely recognized the good infrastructure of internet access promotes the economic wheel of the country, there are many approaches are introducing to establish NGA networks by implementing the new regulation in specific sectors, government subsidies. Currently, the regulatory authority of EU applies the new framework to inspire in the comprehensive the deployment NGA in the European Union. The new access regulation covers NGA (fiber-optic) including the copper-based network.

The future of Next Generation Networks has been argued in the ICT forum, not for the long. However, it is notable that how the development of the market will react to the next step of NGN in the EU market. Existing market players who are operating the NGA core network already and who are coming to deploy NGA access and have promised to install the fiber-optic networks or migrate to it, considered as the market development of NGA networks. To establish high-speed internet access facilities, EU must deploy NGA network, which is fiber-optic based technology. Now there is a big challenge in front of the EU commission that what and how they could adopt the new system in the European member states. European Commission must pay attention to ICT (information and communication technology) sectors because it is one of the potential sectors. ICT creates thousands of jobs and contribute to the production to increase the growth and boost the economy.

The deployment of NGA networks is one of the biggest challenges to the European Commission. The European market is already covered by the copper-based network system, so the demand for NGN would stay in uncertainty at the present situation. Demand uncertainty represents the primitive investment is significant and regulatory interruption causes sunk of investment.

A huge amount of investment requires deploying NGA networks. It is always questionable that with large fixed cost sunk cost what would return at the end of investment in NGN. This demotivates investment and newcomer in the market. NGA (fiber-optic) network shows the optimistic opportunity but on the other hand uncertainty with a high risk of investment.

Consumers in the market would not determine the payment for NGA network service. The consumers might not migrate to NGA networks if even they do so but not be interested to pay the high price for the NGN where they could get copper-based service at low price.

Regulatory issues always affect the telecoms markets because it has uncertain characteristics. The regulations of telecoms markets and its framework randomly switches and that creates the biggest fear to invest in this sector. The investors could bear in their mind that return of investment would be affected by new regulations and that lead to a future loss. On the other hand, the existing broadband regulation is applied for the copperbased network that would not work out for the fiber-optic network.

\section{Research Objective}

This study aims to draw scratch the future of NGA networks in EU. NGA networks will create opportunity in the networking market but on the other hand, there is a high level of uncertainty also exist. This study will help to create the following understanding:

$>$ Demonstrate the NGN penetration in comparison with NGN deployment in EU;

$>$ Correlate the regulatory approach in this specific industry based on different works of literature.

\section{The Significance of the Research}

This paper will present the on-going scenario of NGA network market in EU and other developed countries in the world as a comparable parameter. Besides that, the possible regulation and investment path will help the EU commission, local government, policymakers, economists and prospective investors to understand the short-term and long-term outcome of NGA networks in EU. This study has been designed to visualize the regulation facts that could be implemented by the regulatory authority in order to attract the local and foreign investors as it is considered one of the largest network-based market in EU. 


\section{Facts of NGN in Europe}

The deployment of NGN is a burning issue in European Union as the target proposed by European Commission in order to foster development and stimulate growth in the digital economy. This study has been done to capture the current scenario of NGN coverage in Europe and covered thirty-one countries including the EU28, Switzerland, Norway and Iceland. In this report, NGA technology includes the VDSL, FTTP and DOCSIS 3.0, as all these technologies are capable of meeting the Digital Agenda objective, download speed over 30 Mbps. A separate comparison has also been shown only based on FTTP technology as it provides the highest service internet package among all of them. The annual data has been collected from European Commission website based on the most recent dataset from 2013 to till the end of 2017 and this data represents national and rural level NGA coverage based on the number of households passed by. Moreover, the coverage by broadband network capable of at least $30 \mathrm{Mbps}$ and at least $100 \mathrm{Mbps}$ has also been included in the study. Besides, the progress of the NGA and FTTP deployment of the aforementioned countries are also captured over the last five years and a linear trend has been depicted to see how the countries will achieve the maximum coverage until 2020 if this trend remains same.

\section{Country Comparison of NGA Coverage}

The NGA coverage includes VDSL, FTTP and DOCSIS 3.0, as all they are capable of delivering speed of at least $30 \mathrm{Mbps}$. The main objective of Digital Agenda proposed by EC is to ensure the speed at least at this level by 2020.

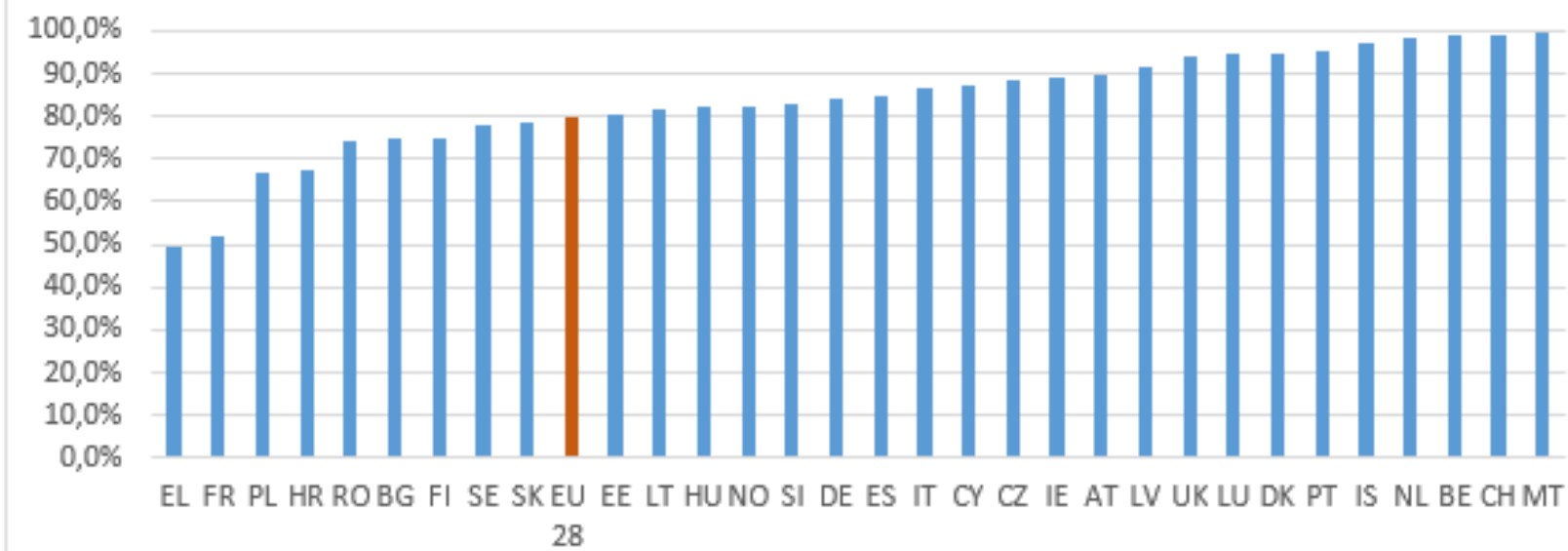

Source: Own elaboration

Figure 1. Total NGA coverage by country ( $\%$ of households), 2017

The above chart represents that the highly urbanized countries have the maximum coverage of NGN, where Malta is the only country having full coverage of NGA technology. Switzerland, Belgium, Netherlands and Iceland are the countries that have the NGA coverage above $95 \%$ level.

There is a significant difference in NGA coverage among the thirty-one countries due to having different strategies and plans towards NGA deployment. Among the thirty-one countries, nine countries are still below the average level of EU28 that is $80.1 \%$. Few countries like Greece, France recorded very low coverage below $52 \%$ compared to the highest performing countries.

The scenario differs significantly when it takes account only FTTP technology. The below chart shows that the average coverage of EU28 (26.8\%) in Europe by individual technology, FTTP is relatively much lower than the combine NGA technology. Eleven countries recorded a lower level of FTTP coverage below EU28. In fact, the highest NGA coverage country Malta (23\%) has also a very low coverage with this individual technology, FTTP. Besides Malta, the top coverage countries like Belgium and Netherlands also have the lower coverage of FTTP Technology. These countries mostly rely on DOCSIS 3.0 to provide high-speed internet. In order to meet the objective, countries like Portugal, Latvia, Lithuania, Spain, Sweden, Denmark, Iceland and Romania have already deployed the fiber-based technology. Greece and Belgium have the lowest level of FTTP coverage, at $0.4 \%$ and $0.8 \%$ respectively. In Germany, Ireland and UK have coverage below $10 \%$ with this technology as they prioritized their strategies based on upgrading the existing VDSL network rather than investing in much expensive fiber technology. These countries view the speed from VDSL and DOCSIS 3.0 is satisfying the current demand. 


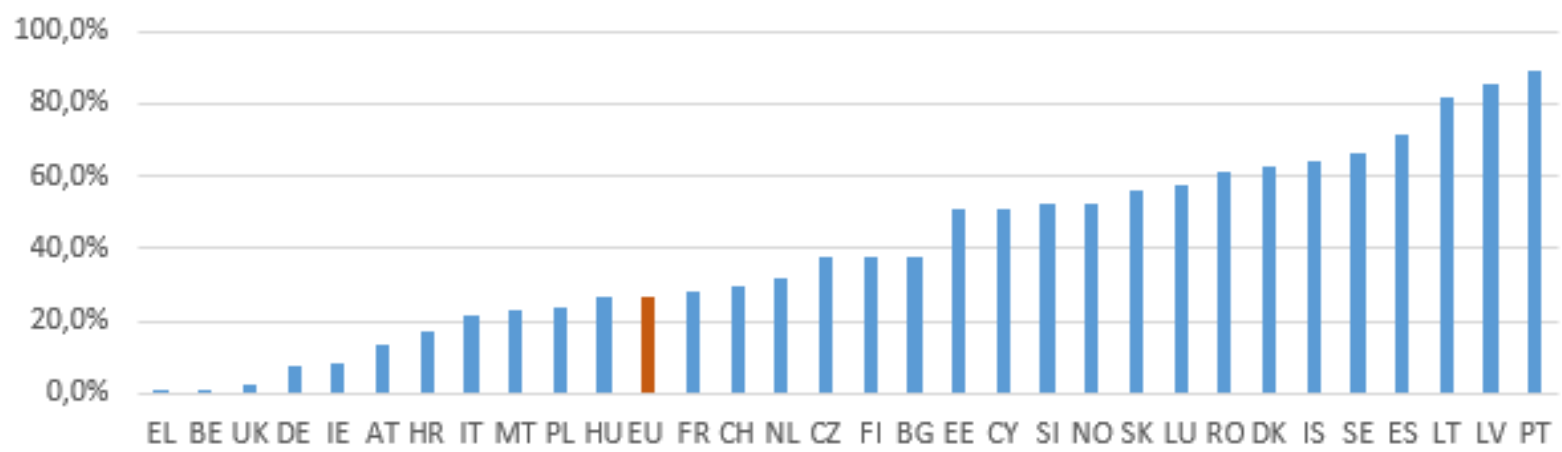

Source: Own elaboration

Figure 2. Total FTTP coverage by country (\% of households), 2017

Looking at NGA, coverage by different countries in the rural area provide different information instead. Different studies show that it is always difficult to invest in rural areas where population density is very low due to the inability to capture the economic profit. The below chart represents the coverage of the combined technology of NGA (VDSL, FTTP, DOCSIS 3.0) in rural areas. Malta is still a leader in NGA coverage in a rural area also as the area size of Malta is very small. However, the rural EU average (46.9\%) is significantly lower than the total EU average (80.1\%). This is still one of the biggest challenges for European countries to ensure the high-speed internet access in rural areas in meeting the targets of Digital Agenda. However, the difference between rural and national NGA coverage is being reduced recently as the deployment starts shifting toward rural areas. However, concerning rural fiber technology coverage, Latvia is in leading position with 69.3\% FTTP coverage by end of 2017. Denmark and Portugal are almost in the same position after Latvia maintaining the coverage level above $50 \%$ in rural areas.

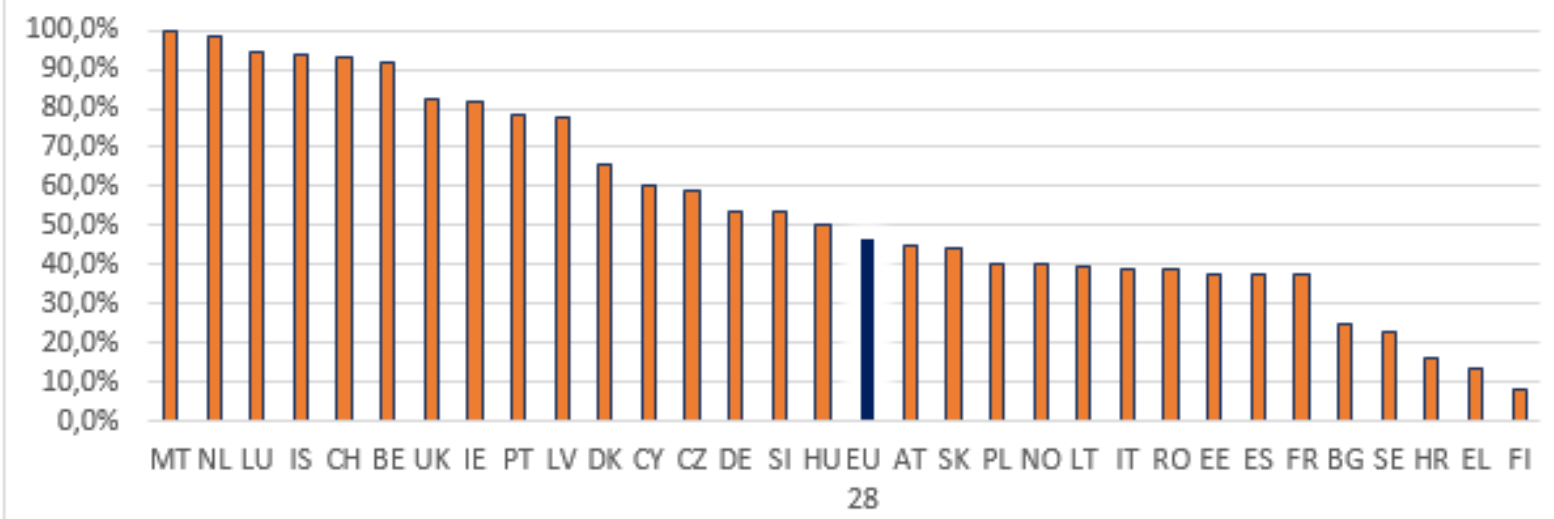

Source: Own elaboration

Figure 3. NGA coverage by country (rural area), 2017

Sixteen countries are below the average of rural FTTP coverage where Belgium, Cyprus Greece and Malta have no access to FTTP services in rural areas.

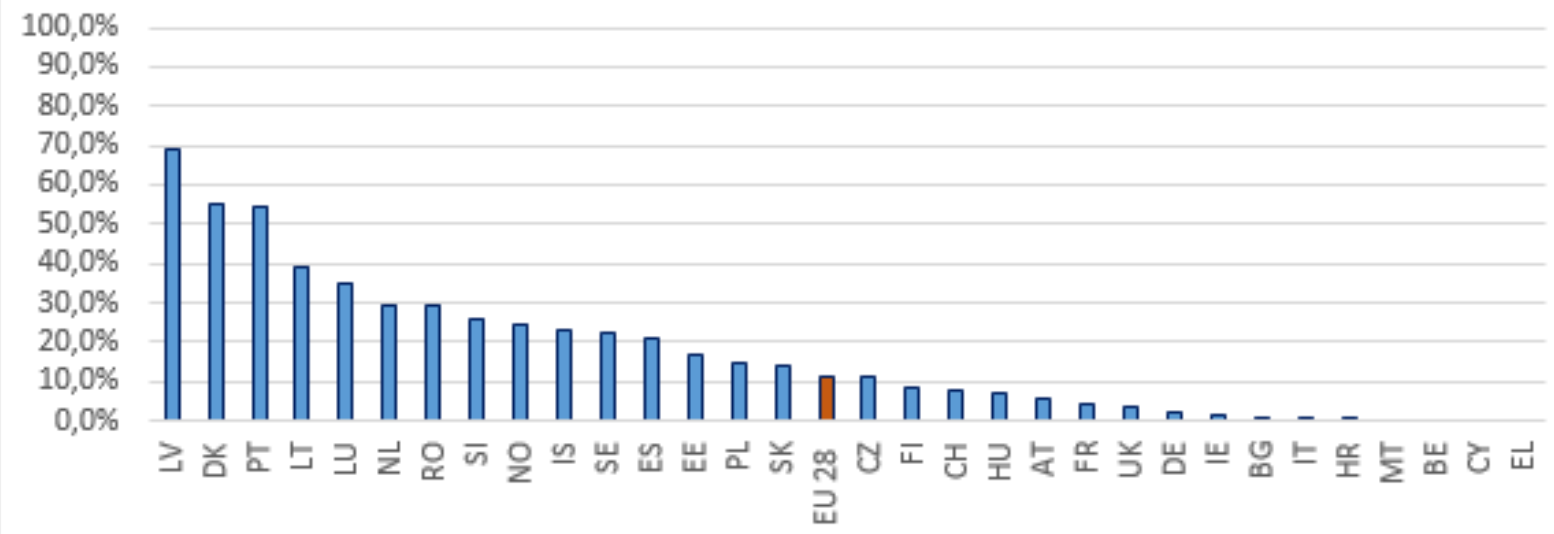




\section{Country Comparison of Speed Categories}

Most of the countries have the availability of serving at least $30 \mathrm{Mbps}$ download speed above average EU 28 (79\%) at the end of 2017. Again, the highest coverage countries at this speed are Malta, Switzerland, Belgium, Netherlands and Iceland. This information provides evidence that the alternative technology VDSL and DOCSIS 3.0 are capable of serving minimum 30 Mbps download speed.

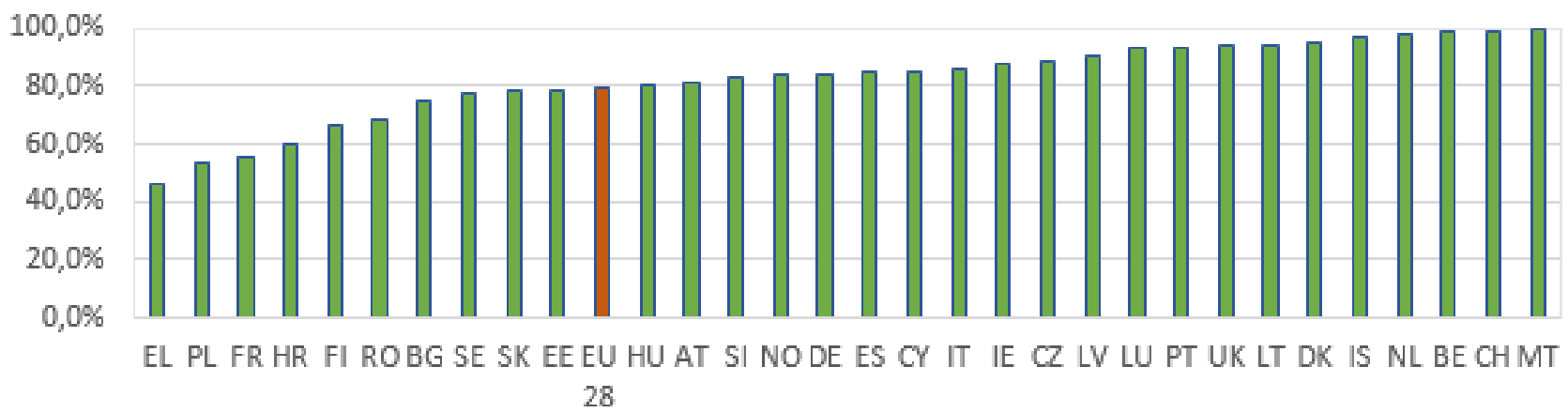

Figure 5. Speed coverage by country, at least $30 \mathrm{Mbps,} 2017$

Source: Own elaboration

However, only the ten countries have the speed below the EU28 average are Greece, Poland, France, Croatia, Finland, Romania, Bulgaria, Sweden, Slovakia and Estonia. Greece is the only country having below $50 \%$ level of this speed. The availability of at least $100 \mathrm{Mbps}$ download speeds in different countries shows that countries with high NGA coverage do not necessarily have a high-level availability of $100 \mathrm{Mbps}$ download speed. For instance, Italy followed 86.8\% NGA coverage whereas in terms of $100 \mathrm{Mbps}$ download speed is only $21.7 \%$, second lowest position after Greece. This scenario is same for UK, Ireland and Bulgaria meaning they had a high-level NGA coverage but a quite low availability of at least $100 \mathrm{Mbps}$ download speed. The average NGA coverage in Europe is $80.1 \%$, EU28 while the average speed coverage of at least $100 \mathrm{Mbps}$ in Europe is $55.1 \%$. Therefore, these countries still face bigger challenges to ensure high-level download speed with their existing technologies. The NRAs have to think about this challenge and its possible solutions within a very short period. However, it is noticeable that the EU as a whole has already achieved $50 \%$ level of households' access to 100 Mbps download speed that was included in Digital Agenda proposed by EC.

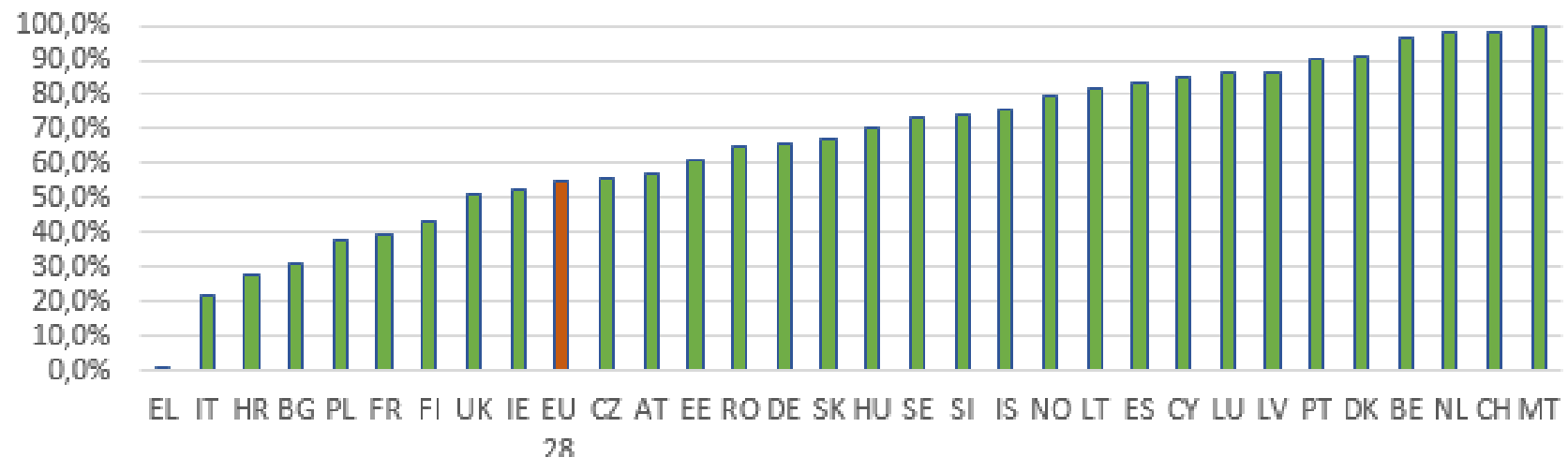

Figure 6. Speed coverage by country, at least 100 Mbps, 2017

Source: Own elaboration

\section{EU Progress of NGA and FTTP Coverage by Country}

The progress of different countries in terms of NGA coverage are also portrayed by below chart. The chart indicates that Italy has a significant progress in deploying NGA technology over the last five years. In 2013, Italy had only $20.33 \%$ level of NGA coverage whereas at the end of 2017 its overall NGA coverage significantly rose to $86.79 \%$, around more than four times higher NGA networks passed by Italian homes, with a $32.96 \%$ point growth. It proves that Italy was very aggressive over the last few years about meeting the objective of the digital agenda. Countries like Ireland, Iceland, and Croatia are also trying hard, with $15 \%$ to $20 \%$ point growth, over the last few years to maximize their NGA coverage. The development progress of the Czech Republic, Slovakia and Spain can also be noticed and they are well above the average development 
progress of EU28, 8.90\% point growth. Countries with highest NGA coverage follow a stagnant growth as they already established their maximum coverage at the beginning.

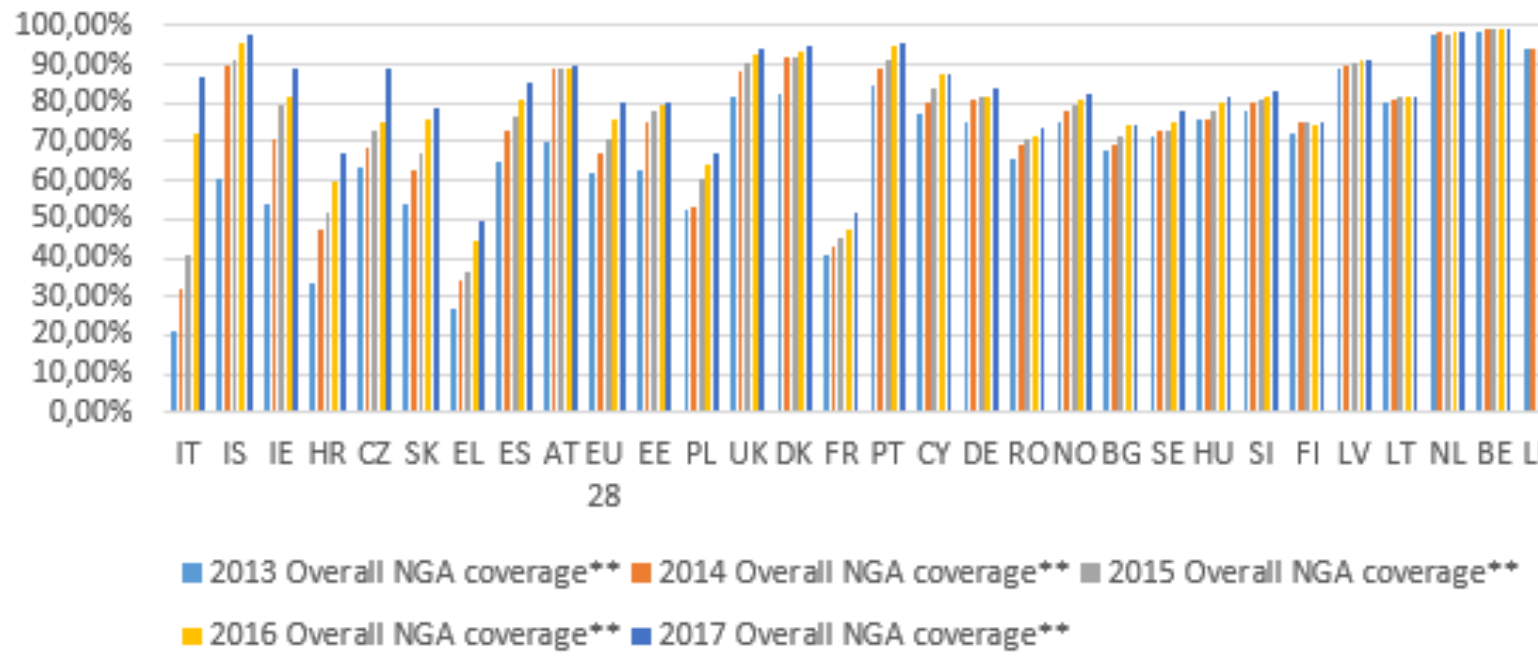

Figure 7. EU progress of NGA coverage by country (\% of households passed), 2013-2017

Source: Own elaboration

While looking at the FTTP progress over the years, Spain has remarkably developed their fiber roll out over the last years. In 2013, the fiber coverage in Spain was $22.75 \%$ but at the end of 2017, it is $71.4 \%$ coverage with fiber technology with $24.34 \%$ point growth. Spain has really set an example for other countries especially who have very low coverage with both speed and fiber technology. Until the end of 2017, the highest coverage countries with fiber technology are Portugal, Latvia and Lithuania. Portugal ranked in terms of development progress of fiber technology after Spain over the last few years. The average progress of fiber development in Europe is quite low, only $6.36 \%$ point growth.

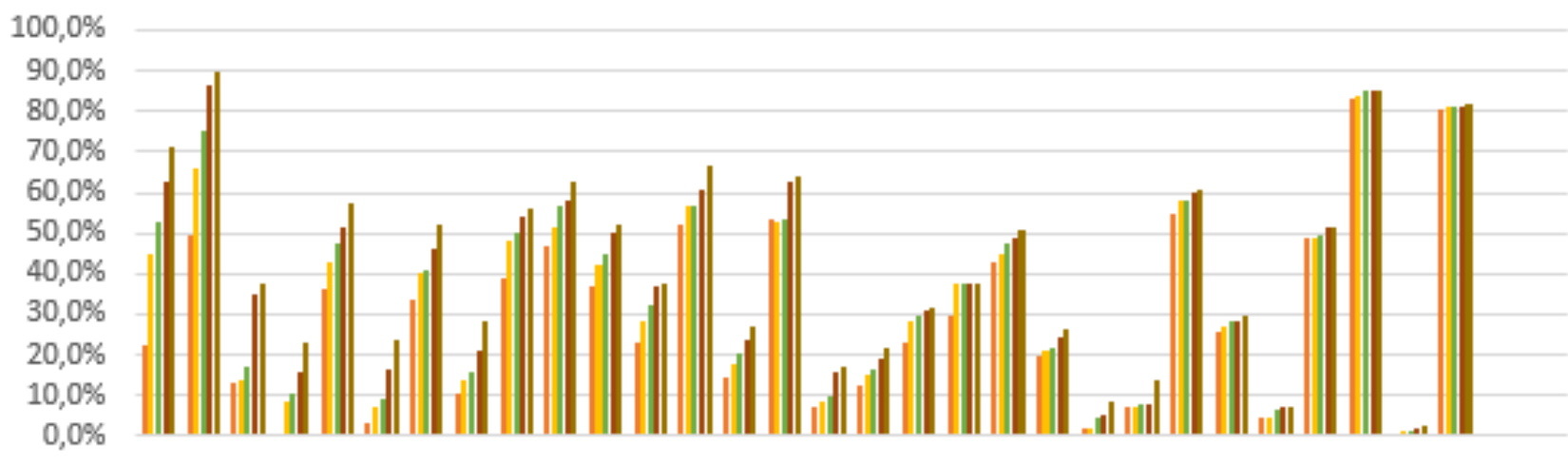

ES PT CZ MT LU PL NOFR SK DK SI BG SEEU IS HR IT NL FI EE HU IE AT ROCH DE CY LV UK LT BE EL 28

— $2013 \mathrm{FTTP} \quad 2014 \mathrm{FTTP} \quad 2015 \mathrm{FTTP} \quad 2016 \mathrm{FTTP} \quad 2017 \mathrm{FTTP}$

Figure 8. EU progress of FTTP coverage by country (\% of households passed), 2013-2017

Source: Own elaboration

\section{Linear Trend of NGA and FTTP Progress across EU}

The below chart represents that if the development trend is linear and goes the same way in the next few years it will be unable to cross $100 \%$ coverage of minimum speed of $30 \mathrm{Mbps}$ by 2020 . For fiber technology, the linear trend is quite disappointing and expected to reach close to $40 \%$ coverage only. 


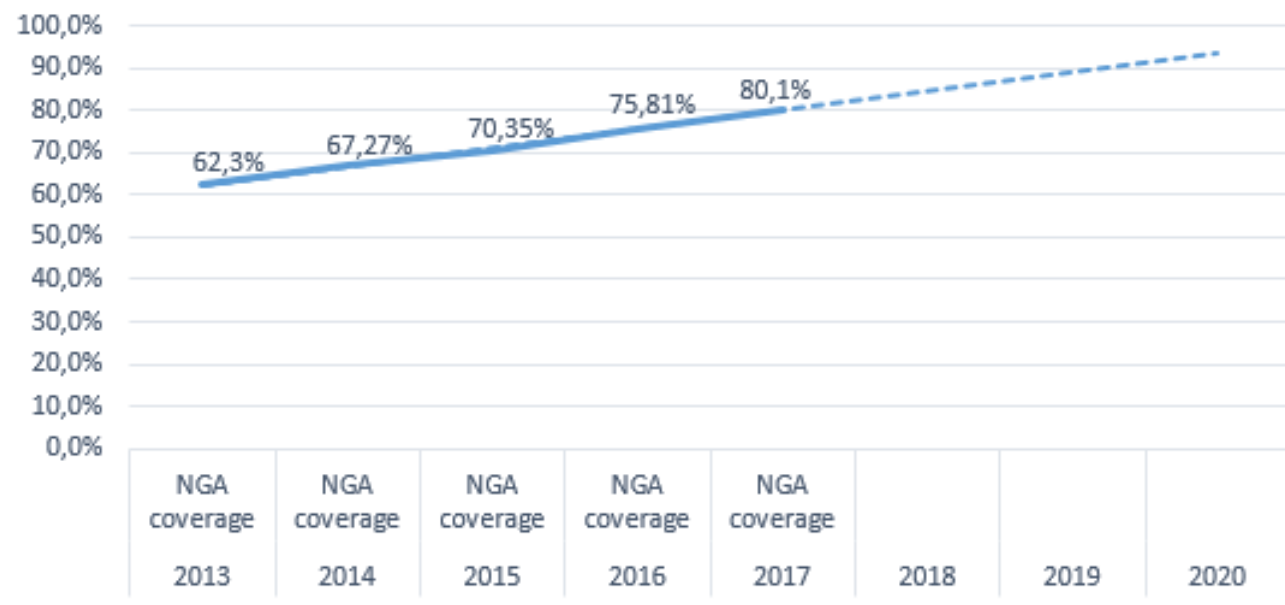

Source: Own elaboration

Figure 9. Linear Trend NGA Penetration - EU 28

It is high time for NRAs to rethink about plan and strategies for deploying fiber technology. The later section will be discussed focusing on regulatory issues related to fiber technology deployment and how the investment in this sector can be encouraged.

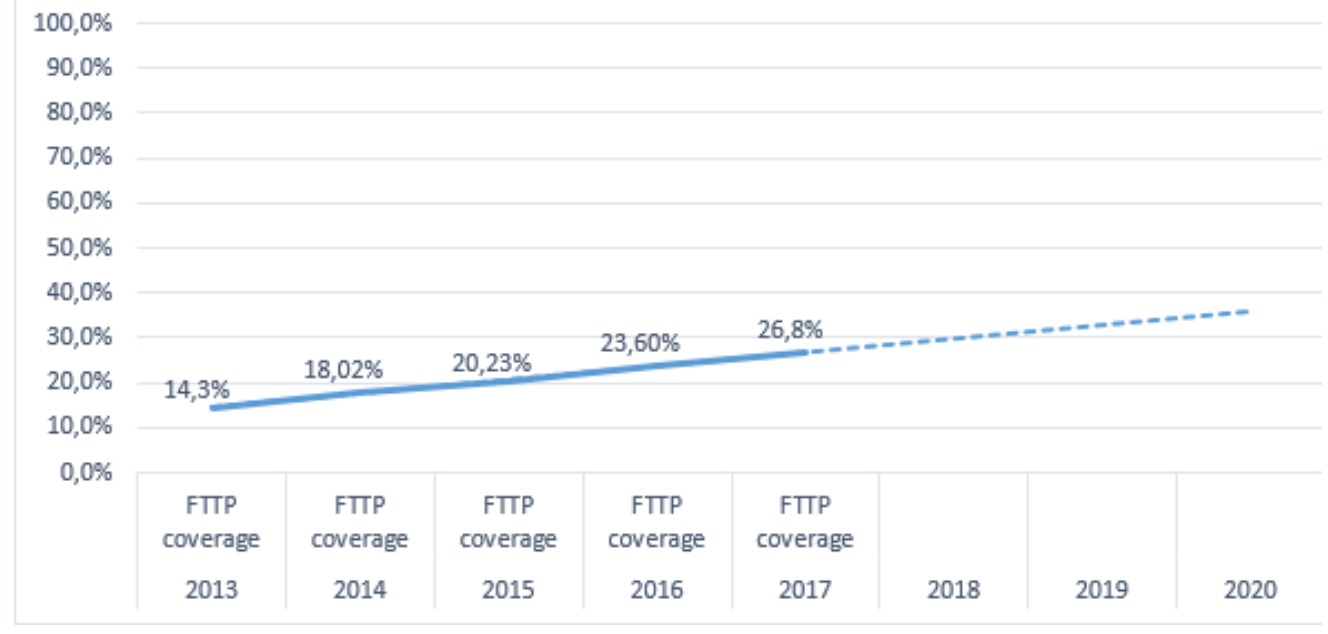

Source: Own elaboration

Figure 10. Linear Trend FTTP Penetration - EU 28

\section{Subscriptions Rate in EU}

The report found from Europe's Digital Progress Report 2017 at European Commission website says that the subscription rates of EU households to fast broadband access of at least $30 \mathrm{Mbps}$ is $27 \%$ that increased significantly from 2010. Netherlands and Belgium are in the leading position in terms of fast broadband takeup while Croatia Italy, Greece and Cyprus are lagging behind.

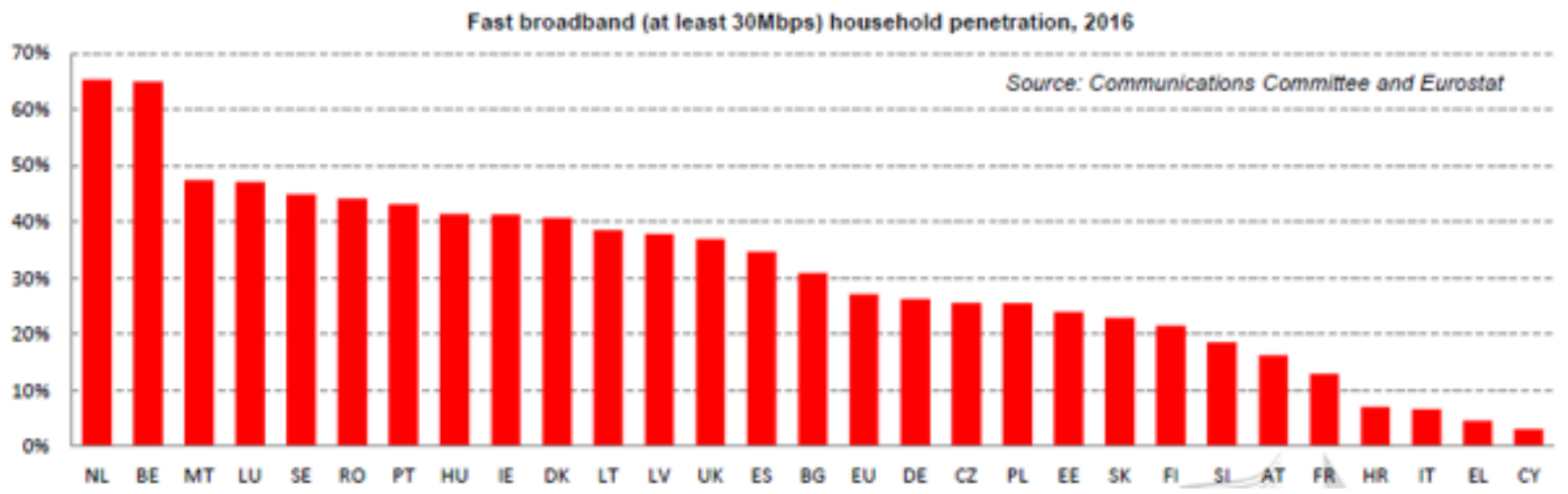

Source: Own elaboration

Figure 11. Subscription rate of at least $30 \mathrm{Mbps,} 2016$ 
The take-up rate of at least $100 \mathrm{Mbps}$ in EU is $11 \%$ while $48.5 \%$ of homes were covered in 2016 of service providing at least $100 \mathrm{Mbps}$. This take-up rate is increasing day by day along with the new offers and services. Romania Sweden and Netherlands are in leading position when it comes to subscription rate of at least $100 \mathrm{Mbps}$. In Greece, Italy, Croatia the take-up rate is quite slow due to the insufficient infrastructure of providing this level of service but in Cyprus, the scenario is a bit different. Despite having, 84.3\% coverage of at least $100 \mathrm{Mbps}$ in Cyprus by the end of 2016, the take-up rate is slow that allows the opportunity for the researchers to keep their eye, especially on this country.

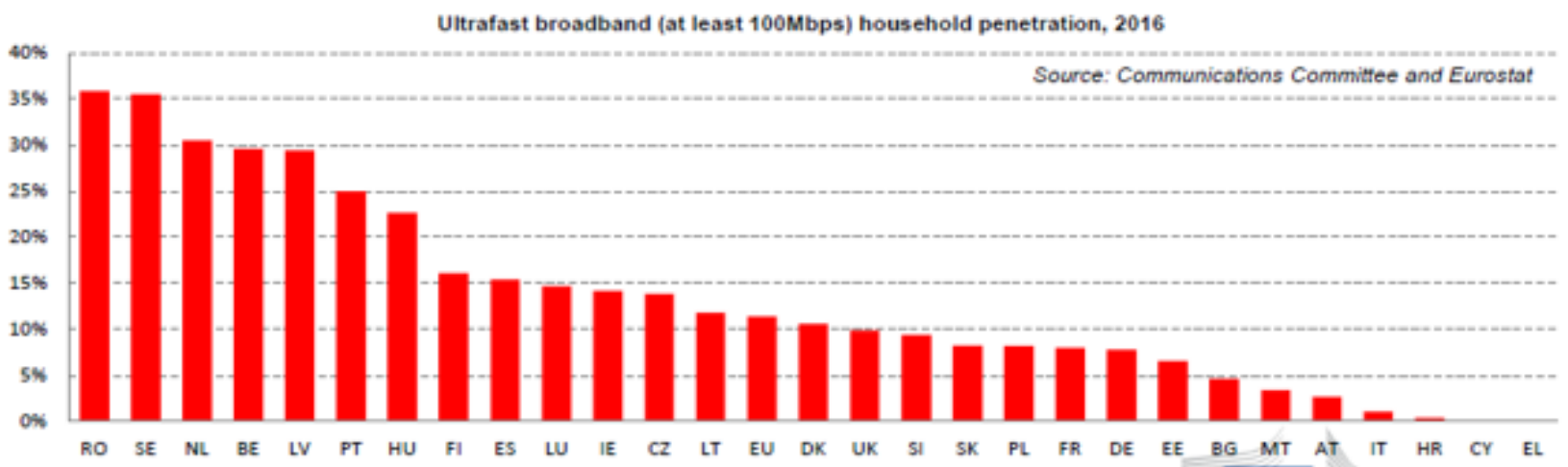

Figure 12. Subscription Rate of Internet by Household Penetration, 2016

Source: Own elaboration

\section{Global Comparison of NGN Adoption}

The Figure from Akamai Technologies, Inc. (2017) says that in the first quarter of 2017, the adoption rate of speed coverage above 25 Mbps was 12\% globally, 16\% increase from the previous quarter and 33\% change by year over year (YoY) basis. The Figure is based on top ten countries by region globally. However, South Korea is in the leading position globally in case of at least $25 \mathrm{Mbps}$ adoption with a double-digit growth from the previous quarter. The USA has the highest quarterly gain (24\%) among all the top ten countries about at least $25 \mathrm{Mbps}$ adoption. If this rate continues, USA will soon be the global leader in NGN adoption. Sweden and Denmark experienced a negative growth quarterly through the yearly growth is positive.

\begin{tabular}{|c|c|c|c|c|}
\hline VI & Country/Region & $\begin{array}{l}\% \text { Above } \\
25 \text { Mbps }\end{array}$ & $\begin{array}{l}\text { Qoo } \\
\text { Change }\end{array}$ & $\begin{array}{c}\text { YoY } \\
\text { Change }\end{array}$ \\
\hline- & Global & $12 \%$ & $16 \%$ & $42 \%$ \\
\hline 1 & South Korea & $40 \%$ & $16 \%$ & $-5.5 \%$ \\
\hline 2 & Norway & $34 \%$ & $0.1 \%$ & $26 \%$ \\
\hline 3 & Sweden & $30 \%$ & $-1.3 \%$ & $16 \%$ \\
\hline 4 & Hong Kong & $28 \%$ & $4.3 \%$ & $20 \%$ \\
\hline 5 & Switzerland & $26 \%$ & $5.6 \%$ & $45 \%$ \\
\hline 6 & Denmark & $25 \%$ & $-4.7 \%$ & $47 \%$ \\
\hline 7 & Singapore & $25 \%$ & $2.8 \%$ & $57 \%$ \\
\hline 8 & Japan & $25 \%$ & $6.8 \%$ & $30 \%$ \\
\hline 9 & Finland & $24 \%$ & $2.1 \%$ & $31 \%$ \\
\hline 10 & United States & $21 \%$ & $24 \%$ & $65 \%$ \\
\hline
\end{tabular}

Figure 13. 25 Mbps Broadband adoption, Top ten countries globally

Source: Akamai Technologies, Inc., 2017

Another important insight from this Figure is all the European countries enjoyed very low growth from the previous quarter than Japan, South Korea and the USA that is alarming for Europe. European policymakers should focus that countries in Europe are lagging behind globally about NGN adoption and find the solutions to cope with the global change in the digital economy.

\section{Literature-based Analysis of Regulatory Issues in EU}

In the previous section, it is noticed that having high NGA coverage countries does not mean they also have the availability of minimum download speed $100 \mathrm{Mbps}$. This is because the NGA technology includes the combination of three technologies- VDSL, FTTP and DOCSIS 3.0. Of these three technologies, two technologies VDSL and DOCSIS 3.0 are upgraded technology of cable network that ensures the minimum speed of $30 \mathrm{Mbps}$. However, it has also been noticed that Malta is always in leading position in speed categories despite having very low FTTP coverage. This is only because Malta is a very small and densely populated country where upgrading the existing technology DOCSIS 3.0 is enough to satisfy its demand. Largest 
countries in Europe by area like France, Germany, and Spain are not capable of delivering the high-speed internet above $100 \mathrm{Mbps}$ level with VDSL and DOCSIS 3.0, as these technologies are associated with distance. These technologies provide maximum speed in a certain area. The more distance it is the less speed is possible to serve by these technologies. So today or tomorrow most of the European countries need fiber technology to ensure high-speed internet if they want to cope with the other big players in the digital economy like the USA, Japan and Korea.

Different works of literature have been found concerning investment incentives in fiber technology. Though investing in fiber technology will ensure the high-speed internet that will foster economic growth it has certain challenges to meet up. The main problem of the deployment of this fiber-based infrastructure is that it is extremely expensive, as it requires high fixed cost and the long-term return. Moreover, the future demand is uncertain; the customer's willingness to pay is also unknown. In addition, the network industry in Europe is highly regulated and NRAs change the regulatory approaches and framework very, often for which investors are not encouraged in this investment. European Commission welcomed the innovative regulatory approaches for encouraging the investment in fiber technology. There are some approaches raised in different pieces of literature that are enumerated below.

\section{Co-investment}

Sometimes, investors do not possess enough capital to invest solely in a fiber-based network, as it requires high capital, to cover the whole area immediately. Therefore, a broader area can be covered by joint investment. When two parties jointly invest in network infrastructure, it is called co-investment, also known as risk sharing model. This model is more effective in rural or semi-urban areas where the population density is very low and investors do not want to invest, as they are not able to recoup their economic profit. With this model, two parties share their risk related to future demand, assets and capital. Agreeing on co-investment allow operators to avoid duplicate deployment of network infrastructure and ensure a wider area of a territory. Access can be granted to third parties by mutual opinion and NRAs need to regulate this to spur the competition so the networks' providers cannot behave collusively and form a monopoly market to lower the competition.

Empirical evidence has been supported co-investment as an alternative mechanism compared to wholesale access price regulation. Nitsche and Wiethaus (2011) shed light on co-investment suggesting two similar types of the firm to invest in the NGN network that will benefit both in terms of investment and consumer welfare. Later, Cambini and Silvestri (2012) use framework with vertically integrated firms focusing not only on consumer welfare but also on social welfare. In fact, they used two methods of co-investment compensation schemes- one is cost based where two parties will share cost and capital for investment not paying each any compensation for using NGN network, the other is co-development where they both will share the cost giving access to third parties with a charge in return. Moreover, Briglauer et al. (2015) focus that inefficient investment- duplication of the network can be avoided by co-investment. This network-sharing model ensures higher welfare gain than any other alternative through avoiding duplication of the network, covering a wider area, and sharing risk and capital. To ensure the high level of coordination may incur higher transaction cost but this can be reduced by ensuring competition in covered areas.

Bourreau, Cambini and Dogan (2012) discussed three type of regulatory regimes- pure access, pure coinvestment, and co-investment with access where the incumbent will build the infrastructure and entrants can wait and the see the market conditions to invest. To capture the impact of co-investment in expanding NGA network Bourreau, Cambini and Hoernig (2016) addressed some key issues. They compare different regulatory regimes in different infrastructure coverage based on the model of Bourreau, Cambini and Dogan (2012) to see if an entrant wants access to the incumbent's network after the investment plan announced by the incumbent. Not only that, but they also focused on the part of from demand side of the market that due to uncertain demand an entrant can also wait until it is feasible to invest when the outcomes are good. They wanted to explain organizational mode of co-investment is not important, that really matters is the impact of co-investment in deploying NGA network to maximize social welfare. That is why they left the type of coinvestment on the market forces to minimize the burden on investors. An insight can be found from their study that entrants should be given the possibility to wait and request the access at a later period when the market demand expands but this will certainly reduce the incentives of early investors turning them also to wait and see.

On the other hand, in a laboratory experiment, Kreamer and Vogelsang (2017) found there is a chance of collusion in case of co-investment. They emphasized that the co-operation becomes good due to good communication between different parties that induce them the form of collusive behavior. Hence, they suggested non-cooperation would be an effective model for the NGN network expansion. However, it is also 
important to mention the study of Balmer (2013) that some of the countries France, Spain, Switzerland, Portugal reaped the benefit of co-investment model by which the wider area has been covered with new infrastructure.

\section{Access Regulation}

Over the last decade, wholesale access regulation is a topic for debate at the European level. Infrastructure providers say open access regulation discourages investors' incentives to deploy and expand in new infrastructures while the NRAs say the mandated access regulation with regulated fee attracts the new entrants in the market, hence enhance the competition as they see a risk of monopoly market structure in the pronounced areas. In the regulatory framework published by European Commission (2012), it has been mentioned that NRAs should carry out three-stage market analysis to restrict the abuse of market power. In the first stage, it is said to define the relevant communication market where regulation can be specified. In the second stage, NRAs are instructed to analyze the level of competition exists in the market to see if at least one of the firms has significant market power (SMP). If SMP is detected at this stage, NRAs should establish the ex-ante regulations on the dominant to ensure the fair level competition in the market.

Regulatory instruments are considered at the wholesale level, generally in the form of access price or product. The former broadband regulations carried out in the telecom market were resale level, bitstream access, shared access and local loop unbundling (LLU) also known as investment ladder that was popularized in European level, especially in the network industry. In each level, entrants can request access on incumbent's networkbased different regulated fee. At the resale level, the access seekers do not need any investment on the core network but the on the local loop the entrants need to make a higher investment on core networks for shaping the differentiated retail products. Due to the access made at the local loop, the service-based competition has become intensified and the long-term goal of the ladder of investment- investing in core network has not been materialized over the years. Vogelsang (2013) discussed in his study that the concept of the ladder of investment has become unsuccessful and failed to create the competition in infrastructure-based competition. Another reason was that for the failure or this hypothesis is that it was never implemented by NRAs as the author initially proposed.

It is also important to recognize that regulations should be symmetric imposing on all firms irrespective of market power. Symmetric regulations are effective in delivering synergy benefits and lowering total cost that increases the utilization of network capacity. In addition, existing network operators can be more efficient by using their current physical infrastructure, especially where it is not economically viable to install the new infrastructure. Indeed, studies from different authors provide evidence that the cost for cable operators are much lower to upgrade their access infrastructures in fiber market than the cost for the incumbent. Briglauer, Cambini, and Grajek (2017) extended their previous study Briglauer et al (2012) by developing a model of investment competition where there are three competitors- an incumbent who has an existing copper-based network, a cable operator and an entrant who wants access in fiber infrastructure. However, only the incumbent is subject to ex-ante regulation to see the effect of asymmetric access regulation. The result represents that the imposed ex-ante regulation diminishes the incentives of incumbents to invest in NGA networks. Vogelsang (2016) also finds that introducing fiber regulation would be detrimental; he suggests either the regulation should not be established or it should be soft regulation keeping in mind the reluctance of investors investing in NGA infrastructure.

\section{Geographical Access Remedies}

One challenge of NGN deployment is that competition can only appear in densely populated (black) areas where different investors will be encouraged to invest in new infrastructure seeing the potential demand of the market. However, there are some grey or white areas where the competition is less, maybe only one investor in the region or the investment is not profitable at all in this infrastructure. For white areas, the least densely populated regions; the investment may be only feasible with the subsidy of government. Therefore, there is a need for ex-ante access rules to differ across regions according to a different level of market competition. Different prices in the areas with a single infrastructure and in the areas with multiple competing infrastructures can be set way to attract new investors investing in NGA network to ensure the countrywide maximum NGA coverage. Bourreau, Cambini and Hoernig (2015) suggest the same idea implementing the geographically differentiated regulation in fiber network as a possible regulatory tool to intensify the competition and investment. 


\section{Findings}

Based on the current scenario of NGN deployment in EU, and a review of most related theoretical and empirical literature the following issues are identified:

Co-investment performs better in terms of network coverage and both parties can be more efficient by sharing the cost, capital and asset and avoiding duplicate network. This model encourages investment with increased social welfare and is preferable when demand is highly uncertain;

$>$ Asymmetric access regulation can be established based on the market dominance of the firms with a proper analysis of the market definition of the relevant market. Deregulation can be made when access is not an essential facility. However, if a deregulation is not viable, regulation should at least be symmetrically applied to all operators irrespective of market dominance. Different literature proves that ex-ante regulation on fiber network hampers the investment incentives of the market. The symmetric regulation is more effective when firms have substantial benefit of cost synergies, (such as passive infrastructures of cable operators);

$>$ Partial geographically differentiated regulation of fiber network increases both the incentive to invest and welfare as the competition level largely varies between urban, suburban and rural areas.

\section{Conclusion}

According to the European commission digital economy is rising at seven times. But Europe is lagging behind in this race related to the fast, reliable and connected digital networks which underpin economies and is an integral part of the business and private lives. The enhanced speed and coverage provided by the next generation access network is considered vital for half of the productivity growth. Therefore, implementing next generation access network will provide oxygen to sustain in the competitive landscape. The only private initiative is not sufficient to adopt NGA network. Therefore, the government initiative to set regulatory framework is a prerequisite to mobilize investment in this sector. The European Commission has set a digital agenda to replace copper to fiber network. Therefore, this study was intended to provide an overview of the current scenario of NGN deployment and the analysis of the most related literature on the regulatory issues in European Union. It is evident that most countries will struggle to meet the goal of DAE targets by 2020. However, there are some positive aspects that might positively affect the NGN deployment at the European level. Co-investment model and different types of access regulation are the most relevant regulatory tools. Policymakers should design the regulatory framework in a way so that the investment incentives in NGA infrastructure are increased to ensure the competition and social welfare.

\section{References}

1. Akamai Technologies, Inc. (2017). The State of the Internet: 1st Quarter, 2017 Report. Available at: https://www.akamai.com/us/en/multimedia/documents/state-of-the-internet/q1-2017-state-of-the-internetconnectivity-report.pdf (Access time: 3 August 2018).

2. Bacache, M., Bourreau, M., \& Gaudin, G. (2014). Dynamic entry and investment in new infrastructures: Empirical evidence from the fixed broadband industry. Review of Industrial Organization, 44(2), 179-209.

3. Balmer, R. (2013). Geographic Regulation and Cooperative Investment in Next Generation Broadband Networks: A Review of Recent Literature and Practical Cases. Paper No. 54080. MPRA.

4. Bourreau, M., Cambini, C. and Dogan, P. (2012). Access Regulation and the Transition from Copper to Fiber Networks in Telecoms. Journal of Regulatory Economics, 45, 233-258.

5. Bourreau, M., Cambini, C., \& Hoernig, S. (2015). Geographical Access Markets and Investment. Information Economics and Policy, 31, 13-21.

6. Briglauer, W., Frübing, S., \& Vogelsang, I. (2015). The impact of alternative public policies on the deployment of new communications infrastructure - a survey. Review of Network Economics, 13(3), 227-270.

7. Briglauer, Wolfgang (2016). How EU sector-specific regulations and competition affect migration from old to new communications infrastructure: recent evidence from EU27 member states. Journal of Regulatory Economics, 48(2), 194-217.

8. Briglauer, W, Cambini, C. \& Grajek, M. (2017). Regulation and Investment in European High-Speed Broadband Infrastructure.

9. Cambini, C., \& Silvestri, V. (2012). Technology investment and alternative regulatory regimes with demand uncertainty. Information Economics and Policy, 24, 212-230.

10.Cave, M. (2006). Encouraging infrastructure competition via the ladder of investment. Telecommunications Policy, 30(3), 223-237. 
11.European Commission (2010). Commission Recommendation of 20 September 2010 on Regulated Access to Next Generation Access Networks (NGA), 2010/572/EU, Brussels.

12.European Commission (2017). Europe's Digital Progress Report - Connectivity. Available at: (https://ec.europa.eu/digital-single-market/en/news/europes-digital-progress-report-2017) (Access time: 10 June 2018).

13.European Commission (2017). Broadband Coverage in Europe 2017. Available at: https://ec.europa.eu/digital-single-market/en/connectivity (Access time: 27 July 2018).

14.Kreamer, J., \& Vogelsang, I. (2017). Co-investments and tacit collusion in regulated network industries: Experimental evidence. Review of Network Economics, 15(1), 35-61.

15.Minamihashi, N. (2012). Natural monopoly and distorted competition: Evidence from unbundling fiberoptic networks. Working paper no. 2012-26, Bank of Canada.

16.Nitsche, R., \& Wiethaus, L. (2011). Access regulation and investment in next generation networks, a ranking of regulatory regimes. International Journal of Industrial Organization, 29(2), 263-272.

17.Vogelsang, I. (2014). Will the U.S. and EU telecommunications policies converge? A survey. CESIFO Working Paper, No. 4843.

18.Vogelsang, I. (2015). Will the U.S. and EU telecommunications policies converge? A survey. Economia e Politica Industriale. Journal of Industrial and Business Economics, 42, 117-155.

19.Vogelsang, I. (2016). The role of competition and regulation in stimulating innovation telecommunications. Telecommunications Policy, 10.

20.Yoo, C. S. (2014). US vs. European broadband deployment: What do the data say? U of Penn, Institute for Law \& Economics Research Paper, 14-35. 